\title{
Inhibitive, Adsorption Studies on Carbon Steel Corrosion in Acidic Solutions by New Synthesized Benzene Sulfonamide Derivatives
}

\author{
A. S Fouda ${ }^{1, *}$, A.M. Eldesoky ${ }^{2}$, M.A.Diab ${ }^{3}$ and A.Nabih ${ }^{2}$ \\ ${ }^{1}$ Department of Chemistry, Faculty of Science, El-Mansoura University, El-Mansoura-35516, Egypt \\ ${ }^{2}$ Engineering Chemistry Department, High Institute of Engineering \&Technology (New Damietta), \\ Egypt and Al-Qunfudah Center for Scientific Research (QCSR), Chemistry Department, Al-Qunfudah \\ University College, Umm Al-Qura University, KSA. \\ ${ }^{3}$ Department of Chemistry, Faculty of Science, Damietta University, Damietta, Egypt \\ "E-mail: $\underline{\text { asfouda@mans.edu.eg }}$
}

doi: $10.20964 / 2016.12 .47$

Received: 20 July 2016/ Accepted: 31 August 2016 / Published: 10 November 2016

The inhibitive action of some organic derivatives, namely (NN- azanediyl bis (ethane-2,1diyl))bis (4dodecyibenzenesulfonamide), NN- ((ethane-1,2, diylbis (azanediyl)) bis (ethane-2,1-diyl)) bis(4dodecylbenzenesulfonamide), NN-(((azanediylbis(ethane-2,1diyl))bis(azanediyle))bis(ethane-2,1diyl))bis(4-dodecylbenzenesulfonamide),NN-(3,6,9,12-tetraazateradecane-1,14-diyl)bis(4-dodecyl benzene sulfonamide) against the corrosion of CS (CS) in $1 \mathrm{M} \mathrm{HCl}$ solutions has been tested using gravimetric, (EIS) electrochemical spectroscopy impedance, Tafel polarisation, and (EFM) electrochemical modulation frequency methods. The protection efficiency rise with improving inhibitor doses and lower with temperature rising. Potentiodynamic method demonstrated that Benzene sulfonamide Derivatives play as mixed type inhibitors. The molecule adsorb on the surface of CS follow adsorption isotherm Temkin and was adherent on the molecular size and molecules centres which active. Quantum modelling was utilized to gain the electronic and structural effects are related to the efficiencies of inhibition. The data obtain showed improvement in efficiencies for inhibition with raising the dose of inhibitor. All methods employed were in reasonable agreement with protective efficiency values.

Keywords: CS corrosion, $\mathrm{HCl}$, Benzene sulfonamide derivatives, EFM, EIS. Temkin isotherm

\section{$\underline{\text { FULL TEXT }}$}

(C) 2016 The Authors. Published by ESG (www.electrochemsci.org). This article is an open access article distributed under the terms and conditions of the Creative Commons Attribution license (http://creativecommons.org/licenses/by/4.0/). 